\title{
THE DEVELOPMENT OF AN INTERVENTION TO MANAGE PAIN IN AMAXHOSA WOMEN LIVING WITH HIV/AIDS
}

\begin{abstract}
The profile of HIV/AIDS has changed from that of a terminal illness to one of a chronic debilitating disease which has the potential to become terminal. Once the challenge of averting death from a disease is met, the next step is to maximise quality of life for those living with on-going symptoms such as pain. Despite being a problem in HIV/AIDS, pain remains undertreated. As pharmacological interventions for pain in HIVIAIDS have limited efficacy, a multidisciplinary management model which is effective in chronic pain disorders may be a viable option. A three-step process was followed to develop an evidence-based intervention to manage pain in people living with HIVI AIDS. The process comprised a literature review, field surveys and community consultation. A six-week peer-led exercise and education intervention called "Positive Living" was developed as a result of this process. The theoretical
\end{abstract} model, educational content, exercise prescription and skills acquisition methods applied in the intervention are presented. In addition, factors concerning training, delivery, feasibility and acceptability of the intervention are discussed.

\section{KEY WORDS: HIVIAIDS; INTERVENTION; PAIN; EXERCISE; EDUCATION}

\section{INTRODUCTION}

The human immunodeficiency virus (HIV) and the acquired immune deficiency syndrome (AIDS) have had a devastating impact worldwide with the developing countries of Sub-Saharan Africa bearing the brunt of the pandemic. The 2011 UNAIDS Fact Sheet reported that in South Africa there were an estimated 5.6 million people infected with the virus: more people than in any other single country (UNAIDS, 2011). Although the incidence of HIV in South Africa has dropped from $2.4 \%$ in 2001 to $1.5 \%$ in 2009 , the rollout of antiretroviral treatment (ART) has resulted in an increased prevalence with growing numbers of people living with the condition (UNAIDS, 2011).

\section{Corresponding Author:}

Romy Parker,

Department of Health \& Rehabilitation

Sciences,

Anzio Road, Observatory 7925,

Cape Town, South Africa

E-mail: romy.parker@uct.ac.za
In countries where ART has been made available, the profile of HIV/AIDS has changed from that of a terminal illness to one of a chronic debilitating disease which has the potential to become terminal. With ART becoming available to people living with HIV/AIDs in South Africa, a similar transition can be expected with growing numbers of people living with HIV/AIDS living for longer periods of time. Once the challenge of averting death from a disease is met, the next step is to maximise quality of life for those living with on-going symptoms. Research is then driven by the need to gain further insight into symptoms which persist and interventions which address these symptoms effectively to enhance quality of life and minimise symptom impact.

In people living with HIV/AIDS, ongoing symptoms are wide ranging and include pain, anxiety, nausea, vomiting and fatigue; with pain being one of the most commonly reported symptoms around the globe (Ciccolo et al., 2004). Studies conducted in South Africa have reported similar results with between
$74 \%$ and $80 \%$ of South Africans living with HIV/AIDS reporting pain (Mphahlele et al., 2012). The types of pain experienced by people with HIV/ AIDS and the aetiology of such pains are varied. People living with HIV/ AIDS may experience pain as a direct result of the virus on the peripheral or central nervous systems; pain may be due to immune suppression and resultant opportunistic infections; or pain may arise as a result of the side effects of ART (Smith et al., 2002). The pain may also be idiopathic in origin with no clear aetiology or be due to other illnesses not associated with HIV (Kamerman and Mitchell, 2011).

Despite being identified as a problem in people living with HIV/AIDS , pain in people living with HIV/AIDS remains undertreated worldwide (Kamerman and Mitchell, 2011). A review of the literature reporting on the effectiveness of treatment interventions for HIV/AIDS was conducted. These programmes have used varied approaches ranging from didactic group education (Worley et al., 2009); cognitive behavioural therapy 
(Trafton et al., 2012), a combination of peer and expert-led education (Webel, 2010) and expert-led exercise (Fillipas et al., 2006). All these interventions have been reported to have moderate effects on a variety of outcomes in HIV/ AIDS, including health related quality of life and self-efficacy. However, none of these interventions focussed on managing pain. Treatment of pain in HIV/AIDS has focussed on pharmacological approaches, with limited efficacy (Kamerman and Mitchell, 2011).

With pharmacological interventions for pain in HIV/AIDS having limited efficacy, a multidisciplinary management model which is effective in chronic pain disorders may be a viable option (Ostelo et al., 2005). This model focuses on an empowered patient at the centre of a health care team with the patient enabled to access appropriate interventions. A key component of this model is education, with interventions aimed at enabling patients through increasing knowledge and self-efficacy.

As pain is a substantial problem in South Africans living with HIV/AIDS, the aim of this study was to develop an intervention to manage pain in people living with HIV/AIDS.

\section{METHOD}

In order to develop a feasible, evidencebased non-pharmacological intervention to manage pain in people living with HIV/AIDS, a three-step approach was adopted. Initially a literature review was conducted. This was followed by field surveys to establish sites and finally consultation with community members.

Specific information was drawn from the studies identified in the literature review $(\mathrm{a}-\mathrm{g})$ to guide the development of an intervention to manage pain. The specific information explored was categorised according to the following headings: (a) theoretical model; (b) learning style; (c) educational content; (d) exercise; (e) skills development; (f) length of delivery and $(\mathrm{g})$ training.

Field surveys and community consultation guided the final steps in developing the intervention $(\mathrm{h}-\mathrm{i})$. The field surveys established appropriate sites $(\mathrm{h})$ where the intervention could be delivered. Visits to community sites were conducted to determine aspects of access, safety and suitability, including privacy. The final step was community consultation (i); members of the community living with HIV/AIDS were approached and consulted on various aspects including the cultural acceptability of the proposed intervention and suitability of the proposed venue.

\section{RESULTS}

A six-week peer-led exercise and education intervention programme was developed for use in amaXhosa women living with HIV/AIDS and presenting with pain. The intervention programme was developed based on the three-step process described above. The specific information which was drawn from the literature, and used to develop the intervention, will be presented first, followed by the findings from the community interaction.

\section{THEORETICAL MODEL}

The programme was based on self-efficacy theory (Bandura, 1986) using the principles of social learning and cognitive behavioural therapy, such as problem solving and goal setting which aim to achieve behaviour change and build confidence (Lorig and Holman, 2003).

While health education is a cornerstone to improving knowledge, self efficacy and health promotion; didactic education alone does not lead to an empowered patient or a change in behaviour and an empowered patient. Didactic health education programmes have limited effectiveness in managing function in people with chronic diseases (Von Korff et al., 2005). In order for changes in knowledge and beliefs to translate into behaviour changes which will have a positive impact on function and quality of life, cognitive behavioural approaches; primarily through goal setting, need to be adopted (Lorig and Holman, 2003). Therefore effective patient education programmes aim to change knowledge, selfefficacy beliefs and health behaviours in order to improve symptom severity and management, quality of life, adherence and reliance on medical services (Foster et al., 2007).

\section{LEARNING STYLE}

Peer-led education programmes have been successfully implemented in diverse settings for diverse conditions (Webel, 2010, Worley et al., 2009) and are widely recommended for use in programmes designed for people living with HIV/ AIDS (UNAIDS, 1999). Peer-leaders are commonly used in counselling and education programmes to overcome language and cultural barriers to care as well as to alleviate pressurised health care professionals (Worley et al., 2009). In addition, peer-leaders act as models who actively demonstrate the benefits of implementing the knowledge and skills being delivered through a programme or intervention (Lorig and Holman, 2003). Peer-led programmes have been found effective to increase knowledge in people living with HIV/AIDS (UNAIDS, 1999). In addition, peer-led programmes may lead to greater changes in behaviour than expert-led programmes explained by the social learning theory (Bandura, 1986). The peer-led model was adopted to address language and cultural issues, minimise load on health care professionals and facilitate behaviour change through peer modelling.

A further consideration when selecting learning and teaching methods was the use of individual or group formats. Chronic disease and chronic pain management programmes commonly adopt a group approach for delivery of interventions but no differences were found in effect between group and individual treatments (Thorn and Kuhajda, 2006). The advantages of group work include the non-specific effects of treatment gained from patients being able to express themselves in a safe and non-threatening environment, which is enhanced through the sharing of common experiences and challenges (Newton-John and Geddes, 2008). However, group work is not appropriate for all individuals and in order to be effective, groups need to be limited in size and in participants. For example, persons with cognitive impairment, significant mental health disorders or interpersonal problems may not benefit from group work and should be managed individually (Thorn and Kuhajda, 2006).

Group size is recommended to be limited to a maximum of 12 people to ensure that relationships can be developed and facilitation of discussion is possible. Education in larger groups tends to become more didactic as facilitators struggle to manage interactions. In summary, group work is beneficial as a treatment and, when used with appropriately screened patients, is a cost-effective, effective treatment approach. This approach was therefore selected for the intervention programme.

\section{EDUCATIONAL CONTENT}

A workbook titled "Positive Living" based on HIV/AIDS specific educational material (Expert Patients Programme Community 
Interest Company, 2007, Gifford et al., 2005, Treatment Action Campaign, 2007) and on chronic pain educational material (Nicholas et al., 2000), was developed. The workbook aimed to facilitate the development of the core self-management skills of problem solving, decision making, finding and utilizing resources, forming partnerships with health care professionals, and taking action (Lorig and Holman, 2003). To allow for a transfer of knowledge into action (in other words to facilitate skills acquisition) the handbook included an exercise diary, goal setting and problem solving tasks (Lorig and Holman, 2003).

The workbook was divided into six chapters to encourage users to work through the book at regular intervals. Each chapter was designed to be read consecutively and were therefore titled Week 1, Week 2, etc. up to week 6. Each week focussed on a specific topic identified through the literature review (Table 1). At the end of each chapter, action planning forms based on the topic for the week were included in addition to an exercise diary. The final section of the workbook included information on resources and additional action planning and exercise sheets.

\section{EXERCISE}

Aerobic exercise and strength training are safe for use in people living with HIV/ AIDS (O'Brien et al., 2004a, O'Brien et al., 2004b). An aerobic exercise programme was developed using intervals of progressive strength training and stretching based on the American College of Sports Medicine Guidelines (Durstine et al., 2009). The exercises were chosen on the basis of safety, simplicity (no additional equipment required) and efficacy for increasing aerobic fitness and muscle strength. The exercise programme was 20 minutes in length during the first week and was designed to increase by $10 \%$ each week. Instructions for the exercises included in the workbook indicated that all aerobic exercises should be carried out according to the Borg Scale

\begin{tabular}{|c|c|}
\hline Topic for the Week & Content \\
\hline $\begin{array}{l}\text { Week 1: } \\
\text { Self-management and } \\
\text { exercise }\end{array}$ & $\begin{array}{l}\text { What is meant by "self-management" } \\
\text { Self-management steps } \\
\text { Action plans } \\
\text { Exercise } \\
\text { Types of exercise } \\
\text { Steps to success with exercise } \\
\text { An exercise routine }\end{array}$ \\
\hline $\begin{array}{l}\text { Week 2: } \\
\text { Managing common } \\
\text { symptoms of HIVIAIDS }\end{array}$ & $\begin{array}{l}\text { Symptom management } \\
\text { Action charts for common symptoms } \\
\text { Coughing } \\
\text { Depression } \\
\text { Diarrhoea } \\
\text { Fever } \\
\text { Headache } \\
\text { Eye } \\
\text { Nausea and vomiting } \\
\text { Shortness of breath } \\
\text { Sore throat and mouth } \\
\text { Skin problems } \\
\text { Urination problems }\end{array}$ \\
\hline $\begin{array}{l}\text { Week 3: } \\
\text { Stress management }\end{array}$ & $\begin{array}{l}\text { What is stress? } \\
\text { Managing stress } \\
\text { Sleep } \\
\text { Communication with your health carer } \\
\text { Relaxation skills }\end{array}$ \\
\hline $\begin{array}{l}\text { Week 4: } \\
\text { Pain }\end{array}$ & $\begin{array}{l}\text { Causes of pain in HIVIAIDS } \\
\text { Pain self-management }\end{array}$ \\
\hline $\begin{array}{l}\text { Week 5: } \\
\text { Eating well }\end{array}$ & $\begin{array}{l}\text { Balanced nutrition } \\
\text { Dealing with barriers to eating well } \\
\text { Food safety }\end{array}$ \\
\hline $\begin{array}{l}\text { Week 6: } \\
\text { Continuing as a successful } \\
\text { self-manager }\end{array}$ & $\begin{array}{l}\text { Action planning for the future } \\
\text { Reflection on changes }\end{array}$ \\
\hline
\end{tabular}

Table 1: Topics and content of the "Positive Living" workbook level of "somewhat hard"; an effort of $60 \%$ of maximum heart rate (Borg, 1998). Stretching and strengthening exercises selected focused on muscle groups previously targeted in training programmes designed for people living with HIV/AIDS based on recognised patterns of deterioration (Fillipas et al., 2006). The intervention was designed so that no exercises were conducted in the first session of the intervention to allow participants time for familiarisation. However, every subsequent session began with an initial 20 minutes of exercise, progressing weekly.

\section{SKILLS DEVELOPMENT}

An "Agreement of Participation" was developed for use by the participants. This agreement was designed to facilitate a discussion on the confidential nature of the workshops and to encourage commitment to attend and actively participate in the workshops. The discussion on the agreement was also designed to allow participants to introduce themselves and present expectations or requests to the group. The agreement was designed to allow for specific items raised by participants to be added as required. In addition to the practical component of exercise in the intervention programme, the workbook included exercise action planning forms and weekly goal setting and exercise diaries to encourage participants to continue with an exercise schedule at home.

Relaxation is one of the most commonly used approaches in the treatment of chronic pain supported by a large body of literature (Flor and Turk, 2011, Marchand, 2012). In particular, relaxation strategies have been found to be effective for decreasing the frequency and intensity of attacks in chronic headache patients, a critical factor as headaches are one of the most common types of pain reported by people living with HIV/AIDS (Soderberg et al., 2011). While the instruction to "relax" may be regarded as simple, the skill of relaxation is one which requires guided training and practice in order to master (Flor and Turk, 2011). The intervention was designed to conclude every session with a guided relaxation session facilitated by the peer-leader with the aim of developing the skill. In addition, information on relaxation strategies and relaxation scripts were included in the workbook.

\section{LENGTH OF DELIVERY}

Chronic disease self-management and chronic pain self-management programmes 
commonly range from six to ten weeks in length (Foster et al., 2007, Marks et al., 2005). Interventions lasting for longer periods of time have greater drop-out rates which may negatively affect outcome. A widely used patient education model is that developed by the Stanford Patient Education Research Centre where several peer-led chronic disease management programmes have been developed and tested in various cultural and disease groups (Lorig et al., 2005). In these programmes a time period of between six and seven weeks is used as this is regarded as the minimum time required to effect a change in behaviour while also being a period of time which is not regarded as excessively long by patients (Lorig and Holman, 2003). A time period of six weeks was therefore selected for the intervention programme.

\section{TRAINING}

Specific factors were considered for the roll-out of the intervention programme. These related to: identification and training of a peer-leader and maintaining the veracity of the intervention. In order for the intervention to be effective, the characteristics of a suitable peer-leader were considered. Criteria identified for a peerleader included being from the target community, having an appropriate medical and social history, being bilingual and literate in English and isiXhosa to facilitate training. Training of the peer-leader would need to include theoretical training in material covered in the programme. In addition, training in the theory and practical of group exercise and relaxation techniques as well as screening for contraindications to exercise would need to be covered. Finally, the peer-leader would need to be instructed in practical group facilitation skills, goal setting and activity scheduling. Considering these training needs, a minimum training time of 40 hours was proposed for both training and evaluation of theoretical and practical skills. This in-depth training using the developed workbook also aimed to maintain the veracity of the programme.

\section{SITE}

The venue selected for delivery of the programme would need to be easily accessible to the community, secure, sheltered and private. Venues could include community or religious halls, community health centres, and/or schools outside of school hours. The first author visited the community to identify a safe, accessible and private venue.

\section{COMMUNITY CONSULTATION}

The final step in developing the intervention was community consultation. Two amaXhosa women living with HIV/ AIDS were asked to review the intervention both in terms of content and model of delivery. The reviewers were happy with the proposed intervention. Specific concerns of reviewers included the limited level of education of participants and the involvement of mixed gender groups. Both these aspects had been addressed in the design of the intervention. The programme was specifically designed for amaXhosa adult women living with HIV/AIDs with an average of less than seven years of education using educational guidelines. With educational material developed at this level and available in both English and isiXhosa. The programme was not designed for use in mixed gender groups as this may have presented a barrier to effective communication on certain topics, such as sexuality, which culturally are not openly discussed in mixed gender groups.

\section{CONCLUSION}

This paper illustrates the process followed to develop a six-week peer-led exercise and education intervention for the management of pain in people living with HIV/AIDS. The "Positive Living" biopsychosocial intervention was specifically developed for the management of pain in amaXhosa women living with HIV/AIDS. This intervention was piloted with two amaXhosa women living with HIV/AIDS and found to be culturally acceptable and feasible for delivery in a resource-poor urban environment. This intervention now needs to be trialled in a larger randomised controlled study.

\section{REFERENCES}

Bandura, A 1986 Social foundations of thought and action: a social cognitive theory. Englewood Cliffs, NJ, Prentice Hall.

Borg, G 1998 Borg's Perceived exertion and pain scales.Champaigne, IL, Human Kinetics.

Ciccolo, JT, Jowers, EM \&Bartholomew, JB 2004 The benefits of exercise training for quality of life in HIV/AIDS in the post-HAART era. Sports Medicine (Auckland, N.Z.), 34:487-99.

Durstine, JL, Moore, GE \& Durstine 2009 ACSM's exercise management for persons with chronic diseases and disabilities. Human Kinetics Champaign, JL.

Expert Patients Programme Community Interest Company 2007 Self-management of Long-term Health Conditions: A handbook for people with chronic disease. Boulder, Bull Publishing Company.

Fillipas, S, Oldmeadow, LB, Bailey, MJ \& Cherry, CL 2006 A six-month, supervised, aerobic and resistance exercise program improves self-efficacy in people with human immunodeficiency virus: a randomised controlled trial. Australian Journal of Physiotherapy, 52:185-190.

Flor, H \& Turk, DC 2011 Chronic pain: an integrated biobehavioral approach, Seattle, IASP Press.

Foster, G, Taylor, SJ, Eldridge, SE, Ramsay, J \& Griffiths, CJ 2007 Self-management education programmes by lay leaders for people with chronic conditions. Cochrane Database of Systematic Reviews, CD005108.

Gifford, AL, Lorig, K, Laurent, D \& Gonzalez, V 2005 Living well with HIV \& AIDS, Boulder, Bull Publishing Company.

Kamerman, PR \& Mitchell, D 2011 Current perspectives on HIV-related pain and its management: insights from sub-Saharan Africa. Pain Management, 1:587-596.

Lorig, KR \& Holman, H 2003 Self-management education: history, definition, outcomes, and mechanisms. Annals of Behavioural Medicine, 26:1-7.

Lorig, KR, Hurwicz, ML, Sobel, D, Hobbs, M \& Ritter, PL 2005 A national dissemination of an evidence-based self-management program: a process evaluation study. Patient Education and Counseling, 59:69-79.

Marchand, S 2012 Nonpharmacological Pain Treatments. The Phenomenon of Pain. Seattle: IASP Press.

Marks, R, Allegrante, JP \& Lorig, K 2005 A review and synthesis of research evidence for self-efficacyenhancing interventions for reducing chronic disability: implications for health education practice (part I). Health Promotion Practice, 6:37-43.

Mphahlele, NR, Mitchell, D \& Kamerman, PR 2012 Pain in ambulatory HIV-positive South Africans. European Journal of Pain, 16:447-458

Newton-John, TR \& Geddes, J 2008 The non-specific effects of group-based cognitive--behavioural treatment of chronic pain. Chronic Illness, 4:199-208.

Nicholas, MK, Molloy, A, Tonkin, L \& Beeston, L 2000 Manage your pain: practical and positive ways of adapting to chronic pain, Sydney, ABC Books. 
O'Brien, K, Nixon, S, Glazier, RH \& Tynan, AM 2004a Progressive resistive exercise interventions for adults living with HIV/AIDS. Cochrane Database Systematic Reviews, CD004248.

O'Brien, K, Nixon, S, Tynan, AM \& Glazier, RH 2004b. Effectiveness of aerobic exercise in adults living with HIV/AIDS: systematic review. Medicine and Science in Sports and Exercise, 36:1659-66.

Ostelo, RW, Van Tulder, MW, Vlaeyen, JW, Linton, SJ, Morley, SJ \& Assendelft, WJ 2005. Behavioural treatment for chronic low-back pain. Cochrane Database Systematic Reviews, CD002014.

Smith, MY, Egert, J, Winkel, G \& Jacobson, J 2002 The impact of PTSD on pain experience in persons with HIV/AIDS. Pain, 98:9-17.

Soderberg, EI, Carlsson, JY, Stener-Victorin, E \& Dahlof, C 2011 Subjective well-being in patients with chronic tension-type headache: effect of acupuncture, physical training, and relaxation training. Clinical Journal of Pain, 27:448-56.

Thorn, BE \& Kuhajda, MC 2006 Group cognitive therapy for chronic pain. Journal of Clinical Psychology, 62:1355-66.

Trafton, JA, Sorrell, JT, Holodniy, M, Pierson, H, Link, P, Combs, A \& Israelski, D 2012 Outcomes associated with a cognitive-behavioral chronic pain management program implemented in three public HIV primary care clinics. The Journal of Behavioural Health Services and Research, 39:158-73.

Treatment Action Campaign 2007 HIV in our lives, Cape Town

UNAIDS 1999 Peer Education and HIV/AIDS: Concepts, uses and challenges. Joint United Nations Programme on HIV/AIDS.

UNAIDS 2011 World AIDS Day Report. WHO/ UNAIDS.

Von Korff, M, Balderson, BHK, Saunders, K, Miglioretti, DL, Lin, EHB, Berry, S, Moore, JE \& Turner, JA 2005. A trial of an activating intervention for chronic back pain in primary care and physical therapy settings. Pain. 113:323-330.

Webel, AR 2010 Testing a peer-based symptom management intervention for women living with HIV/AIDS. AIDS Care, 22:1029-40.

Worley, S, Didiza, Z, Nomatshila, S, Porter, S, Makwedini, N, Macharia, D \& Hoos, D 2009 Wellness programmes for persons living with HIV/ AIDS: Experiences from Eastern Cape province, South Africa. Global Public Health, 4:367-385. 